\title{
Análise textual com IRaMuTeQ de pesquisas recentes em História da educação matemática no Brasil: um exemplo de Humanidades Digitais
}

\author{
Yohana Taise Hoffmann* \\ Edgar Bisset Alvarez ${ }^{\star \star}$ \\ Yohannis Martí-Lahera***
}

\section{Artículo recibido: \\ 24 de marzo de 2019 \\ Artículo aceptado: \\ 14 de noviembre de 2019 \\ Artículo de investigación}

\section{Resumo}

O objetivo deste trabalho é analisar a produção de conhecimento na História da educação matemática (HEM) na perspectiva das Humanidades Digitais, a partir de teses de mestrado e doutorado, realizadas nos anos de 2012 e 2017 no Brasil. A amostra está composta por 52 teses e o software IRaMuTeQ foi utilizado para a análise multidimensional de seus resumos. A análise de frequência de palavras tornou possível a identificação de temáticas e metodologias; enquanto a análise fatorial de correspondência permitiu 1) contextualização semântica e 2) visualizar as distâncias

* Programa de Pós-Graduação em Educação Científica e Tecnológica (PPGECT), Universidade Federal de Santa Catarina (UFSC), Brasil_yohana.thc@gmail.com

** Centro de Ciências da Educação (CED), Universidade Federal de Santa Catarina (UFSC), Campus Professor João David, Brasil edgar.bisset@ufsc.br

*** Dirección de Información de la Universidad de La Habana, Cuba ymarti@gmail.com

INVESTIGACIÓN BIBLIOTECOLÓGICA, vol.34, núm. 84, julio/septiembre, 2020, México, ISSN: 2448-8321 pp. 103-133 
entre o corpus textuais (resumos dos trabalhos). No Brasil, a evolução da HEM mostra aumento no número de trabalhos, diversificação de temas e metodologias. Nos anos analisados, a formação de professores é o principal tópico de interesse. A hermenêutica da profundidade é o principal referencial teórico-metodológico nas teses de 2017. Os resultados mostram a influência dos grupos de pesquisa nas agendas de pesquisa das universidades. Os resultados confirmam a utilidade das ferramentas de Humanidades Digitais, especificamente aquelas relacionadas à mineração de texto, para analisar a evolução da produção de conhecimento na HEM.

Palavras-chave: Humanidades Digitais; História da Educação Matemática; Mineração de Texto

Análisis textual con IRaMuTeQ de investigaciones recientes en historia de la educación matemática en Brasil: un ejemplo de Humanidades Digitales

Yohana Taise Hoffmann, Edgar Bisset Alvarez y Yohannis Marti-Labera

\section{RESUMEN}

El objetivo de este trabajo es analizar la producción de conocimiento en historia de la educación matemática (HEM) bajo la óptica de las Humanidades Digitales, a partir de tesis de maestría y doctorado realizadas en 2012 y 2017 en Brasil. La muestra está compuesta por 52 tesis y se utilizó el software IRaMuTeQ para el análisis multidimensional de sus resúmenes. El análisis de frecuencia de palabras posibilitó la identificación de temáticas y metodologías; mientras que el análisis factorial de correspondencia posibilitó 1) la contextualización semántica y 2) visualizar las distancias entre los corpus textuales (resúmenes de tesis). En Brasil, la evolución de HEM muestra aumento del número de tesis, diversificación de temáticas y metodologías. En los años analizados la formación de profesores es el principal tema de interés. La hermenéutica de profundidad es el principal referente teórico-metodológico en las tesis de 2017. Los hallazgos evidencian la influencia de los grupos de investigación en las agendas de investigación de las universidades. Los resultados confirman la 
utilidad de las herramientas de las Humanidades Digitales, específicamente las relativas a la minería de texto, para analizar la evolución de la producción de conocimiento en HEM.

Palabras clave: Humanidades Digitales; Historia de la Educación Matemática; Minería de Texto

Textual analysis with IRaMuTeQ of recent research in the History of mathematics education in Brazil: an example of Digital Humanities

Yohana Taise Hoffmann, Edgar Bisset Alvarez and Yobannis Marti-Labera

Abstract

In this paper, we aim to analyze the knowledge production in the History of mathematics education (HEM), through the lens of Digital Humanities and taking into consideration master and doctoral thesis presented in 2012 and 2017 in Brazil. Our sample is composed of 52 documents. A multidimensional analysis was carried out on abstracts, using IRa$\mathrm{MuTeQ}$ software. Topics and methodologies were determined by word count frequency in the sample; while the correspondence factorial analysis was used 1) for semantic contextualization purpose, and 2) to visualize distances between textual corpuses (thesis and dissertation abstracts). In Brazil, HEM evolution shows an increase in the number of documents, topics and employed methodologies. Teacher curriculum was the hot topic and depth hermeneutics its main theory and methodological framework in 2017. Our findings illustrated the influence of research groups in the research agendas of universities. In addition, the results confirm that Digital humanities tools and more precise text mining tools, are useful to analize evolution of knowledge production in HEM

Keywords: Digital Humanities; History of Mathematics Education; Text Mining 
$\mathrm{N}_{\mathrm{e}}^{\mathrm{o}}$ os últimos anos, a História da educação matemática (HEM) no Brasil está em processo de constituição de um campo (ou subcampo) científico. Podemos afirmar isso por conta da produção científica na área, como, por exemplo, teses e dissertações, criação de grupos de pesquisas, eventos e revistas temáticas. Em relação aos eventos, podemos destacar o Congresso Iberoamericano de História da Educação Matemática (CIHEM), cuja primeira edição ocorreu no ano de 2011 em Portugal, e no ano de 2019 realizar-se-á a quinta edição na Colômbia. Outro evento de destaque é o Encontro $\mathrm{Na}$ cional de Pesquisa em História da Educação Matemática (ENAPHEM), cuja primeira edição foi idealizada logo após o I CIHEM, ocorrendo no ano de 2012 no estado da Bahia. Vários pesquisadores brasileiros analisaram a pertinência de promover um evento nacional a fim de reunir toda comunidade de pesquisadores na área. Assim, a última edição deste evento ocorreu em 2018, no estado do Mato Grosso do Sul.

A partir da realização das edições do ENAPHEM, são organizados livros a fim de reunir os resultados das reflexões presentes nos eventos, como uma contribuição para as pesquisas que investigam a HEM. Até o momento têmse: História da Educação Matemática no Brasil (Valente, 2014), referente ao I ENAPHEM, realizado no ano de 2012; Pesquisa em História da Educação Matemática no Brasil: sob o signo da pluralidade (Garnica, 2016), referente ao II ENAPHEM, realizado no ano de 2014; e História da Educação Matemática e Formação de Professores (Dassie e Costa, 2018), referente ao III ENAPHEM, realizado no ano de 2016.

Cabe destacar, como um espaço para a socialização das pesquisas que investigam a HEM, o Seminário Internacional de Pesquisa em Educação Matemática (SIPEM), assim como, o livro de Ribeiro et al. (2018) que apresentou um panorama das pesquisas na área de educação matemática no Brasil, em um determinado momento no tempo. Em particular, é o resultado das discussões iniciadas no VI SIPEM, com foco principal para as pesquisas dos 13 grupos de trabalhos (GT). Seus capítulos refletem a diversidade de temas de pesquisa dos GT, contemplando questões relacionadas ao ensino e aprendizagem da matemática em todos os níveis de ensino - desde os primeiros anos até a matemática universitária - e englobando questões de história, filosofia, linguagem e cognição, tecnologia, inclusão, avaliação, formação de professores, modelagem matemática e ensino de estatística.

Segundo Coppe et al. (2018), os primeiros trabalhos apresentados da HEM no SIPEM, datam do II SIPEM, realizado no ano de 2003, com quatro pesquisas aprovadas, alocadas no GT 5 - História da Matemática e Cultura. 
"In SIPEM VI, referenced researchers in the area of mathematics education began to appear with publications in the history of mathematics education, such as the work done by Ubiratan D'Ambrosio, Wagner Valente, Gert Schubring, and Maria Ângela Miorim" (Coppe et al, 2018: 117). Seis dos 22 estudos apresentados pertenciam ao eixo da HEM.

During SIPEM VI, the works used documentary and oral sources and, for the most part, used explicitly contributions of cultural history as a theoretical-methodological perspective, referenced in authors such as Peter Burke and Antoine Prost. Studies that include historical perspectives found in school subjects are also mobilized in most texts. In a specific way, one of the studies used the contributions of oral history, and another, Foucault's philosophical perspective. (Coppe et al, 2018: 117)

Desta forma, no ano de 2018 ocorreu o VII SIPEM, inaugurando o GT15 referente a HEM, a iniciativa para a criação do mesmo ocorreu no ano de 2016 na Sociedade Brasileira de Educação Matemática (SBEM) pela proposição de pesquisadores que atuam na HEM reunidos em diversos Grupos de Pesquisas, segundo os coordenadores do GT, Maria Cristina Araújo de Oliveira e Antonio Vicente Marafioti Garnica (2018).

Nesse processo de constituição de um campo científico, em relação ao lado formal do universo científico, Fleck ([1935] 2010: 85) menciona a seguinte estrutura social: "Há uma hierarquia científica, grupos, adeptos e adversários, sociedades e congressos, periódicos, instituições de intercâmbio etc. O portador do saber é um coletivo bem organizado, que supera de longe a capacidade de um indivíduo".

Corroborando com o autor supracitado, percebemos que a HEM ainda está em processo de constituição. Diante disso é importante analisar a produção científica e perceber os caminhos que as pesquisas vão seguindo. Podemos pensar como as pesquisas da HEM, em particular a produção acadêmica como teses e dissertações, no Brasil vem se desenvolvendo? Quais são as temáticas e problemas de pesquisas? A partir de quais referenciais teóricos e metodológicos essas pesquisas estão mobilizando?

Nesse sentido, a utilização de software que realizam análises textuais discursivas, bem como disponibilizam uma visualização gráfica simplificada de uma estrutura de dados complexa, podem auxiliar diretamente e servir como subsídio para os estudos na área, contribuindo assim para a descoberta de um conhecimento novo.

Assim, o objetivo do artigo é trazer uma abordagem das Humanidades Digitais, utilizando como dados a produção do conhecimento na História da educação matemática (HEM) no Brasil, em particular a produção de teses e 
dissertações nos últimos anos, utilizando como ferramenta para análise dos dados, o software IRaMuTeQ.

Por Humanidades Digitais compreende-se como a "ligação entre a investigação em Humanidades e a incorporação de métodos e ferramentas das Tecnologias Digitais" (Alves, 2016: 91). Ou seja, uma intersecção entre as perspectivas de análises tradicionalmente conhecidas do campo das humanidades, como por exemplo, as análises textuais, associado às novas possibilidades metodológicas advindas das possibilidades mediadas pelo digital.

O termo "Humanidades Digitais", embora tenda a ser encarado como mais um rótulo generalista, surge como um campo interdisciplinar disposto a dar guarida às reflexões e às práticas suscitadas pelas mudanças decorrentes da introdução das tecnologias digitais no universo da cultura e das Unidades de Informação e Cultura. (Almeida e Damian, 2015: 8)

De acordo com Camargo e Justo (2013) a análise textual trata-se de uma especificidade da análise de dados, que analisa desde material transcrito a textos produzidos em diferentes condições, como entrevistas, documentos, entre outros. São relevantes para estudos a respeito dos pensamentos, crenças, ideias, opiniões em relação a um determinado evento.

A análise de dados textuais, ou análise lexical, conforme Lablou (1994) propõe que se supere a dicotomia clássica entre quantitativo e qualitativo na análise de dados, na medida em que possibilita que se quantifique e empregue cálculos estatísticos sobre variáveis essencialmente qualitativas - os textos. Torna-se possível, a partir da análise textual, descrever um material produzido por determinado produtor, seja individual ou coletivamente (um indivíduo ou um grupo), como também pode ser utilizada a análise textual com a finalidade comparativa, relacional, comparando produções diferentes em função de variáveis específicas que descrevem quem produziu o texto. (Camargo e Justo, 2013: 514, grifo do autor)

Um dos recursos para as análises textuais, que compõem um grande volume de dados, é a mineração de texto. Esse conceito está relacionado à descoberta de conhecimento em textos (Knowledge Discovery from Text - KDT), cujos processos foram descritos em 1995 pela primeira vez, por Feldman e Dagan, que descreveram a forma para extrair informações a partir de coleções de textos. Utiliza técnicas de extração, de análise qualitativa e quantitativa de grandes volumes de textos, frases ou apenas palavras. "Na prática, a mineração de textos define um processo que auxilia na descoberta de conhecimento inovador a partir de documentos textuais, que pode ser utilizado em diversas áreas do conhecimento" (Morais e Ambrósio, 2007: 6). 
Para contribuir nesse processo de mineração de texto faz-se necessário a utilização de software e computadores. O software que irá auxiliar na mineração de texto é o IRaMuTeQ. Apresentamos a seguir os recursos e o seu uso, tendo como dados, a produção de teses e dissertações que investigam a HEM no Brasil.

\section{Aspectos metodológicos}

As primeiras pesquisas que investigam a HEM, datam do final da década de 1980 e meados dos anos 1990. De acordo com Brito e Miorim (2016) no ano de 1984 tem-se a primeira dissertação na área, no Programa de Pós-Graduação em Educação da Universidade Federal do Paraná (UFPR). Sendo, em 1995, defendida a primeira tese de doutorado, também no programa em educação pela Universidade Estadual de Campinas (UNICAMP).

Segundo as autoras supracitadas a produção de teses e dissertações na área da HEM tornou-se regular a partir do ano de 2007, com uma tendência crescente de trabalhos. Realizamos uma busca no Catálogo de Teses e Dissertações da Coordenação de Aperfeiçoamento de Pessoal de Nível Superior (CAPES) com a palavra-chave "História da educação matemática", e obtivemos 221 resultados no período de 2000 a 2018, consulta realizada no dia 11 de janeiro de 2019, como podemos observar na Figura 1.

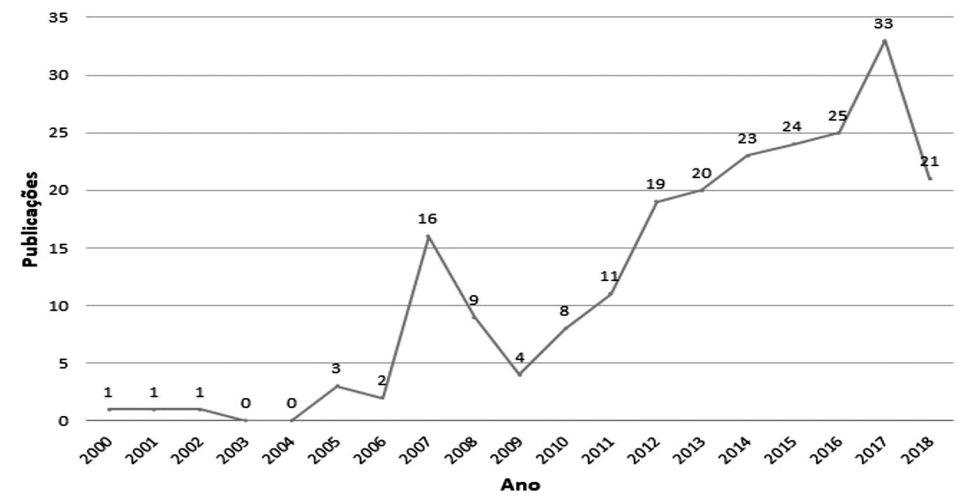

Figura 1. Teses e Dissertações por ano na área da HEM (2000 a 2018) Fonte: elaborado pelos autores

Podemos verificar de acordo com a Figura 1, que a partir do ano de 2007 há um aumento significativo de teses e dissertações defendidas, corroborando com o afirmado por Brito e Miorim (2016). Observando a figura, outro 
destaque é para o ano de 2017 com 33 defesas, sendo então o ano de maior frequência. No período de 2000 a 2018 foram defendidas 118 dissertações, 59 teses, 27 defesas de mestrado profissional e 17 profissionalizações. No entanto, cabe destacar, que o trabalho realizado por Brito e Miorim (2016), apresentou uma visão panorâmica das teses e dissertações produzidas no Brasil, entre os anos de 1971 a 2011, totalizando 200 pesquisas, sendo 148 dissertações e 52 teses. As autoras classificaram os trabalhos em cinco eixos temáticos:

1. História de formação de professores de matemática;

2. História de mudanças curriculares, métodos e práticas educativas em matemática;

3. Histórias de conteúdo e de disciplinas escolares em diferentes níveis de ensino;

4. História de artefatos didáticos relacionados ou dirigidos à educação matemática;

5. História de grupos culturais ou comunidades de prática envolvidos com educação matemática (Brito e Miorim, 2016: 81).

Desta maneira, para a realização da análise textual optou-se pelas teses e dissertações defendidas nos anos de 2012 e 2017, que possuem significativa quantidade de trabalhos defendidos, assim como, correspondendo um período que ainda não foi analisado.

Como mencionado anteriormente o software que iremos utilizar para a realização da análise textual é o IRaMuTeQ (Interface de R pour les Analyses Multidimensionnelles de Textes et de Questionnaires), um software gratuito (http://www.iramuteq.org) desenvolvido por Pierre Ratinaud, junto ao Laboratoire d'Études et de Recherches Appliquées en Sciences Sociales (LERASS) da Universidade de Toulouse, e lançado ano de 2008. Utiliza o pacote estatístico software R (www.r-project.org) e a linguagem de programação Python (www.python.org).

Com o IRaMuTeQ é possível realizar análise de corpus textual e de matrizes. A primeira corresponde ao material escrito, sendo possível analisar textos, entrevistas, documentos, redações etc. Já a segunda envolve categorias variáveis e listas de palavras. Nesse artigo iremos analisar dois corpus textuais, relacionados aos resumos das teses e dissertações do ano de 2012 e 2017.

O software permite realizar análises lexicográficas, que identifica a quantidade de palavras, a frequência média e o número de hapax (palavras com frequência um). Análises de especificidades e análise fatorial de correspondência (AFC), são especialmente indicadas para descrever um grande volume de dados, associando textos com modalidades de uma única variável de caracterização, ou seja, possibilita a comparação (contraste) da produção 
textual destas modalidades. Outro método é a classificação hierárquica descendente (CHD), que classifica os segmentos de texto em função dos seus respectivos vocabulários, formando um esquema hierárquico de classes, e o conjunto deles é repartido em função da presença ou ausência das formas reduzidas. Possui também como recurso a análise de similitude, baseada na teoria dos grafos, permitindo identificar as co-ocorrências entre as palavras e seu resultado traz indicações da conexidade entre as palavras, auxiliando na identificação da estrutura do conteúdo de um corpus textual. Outro recurso que contribui para a visualização de um corpus textual é a nuvem de palavras, que agrupa e organiza as palavras em função da sua frequência. As palavras com maior frequência são as maiores e são colocadas ao centro do gráfico, as menores representam frequências inferiores (Camargo e Justo, 2018).

\section{Coleta e análise dos dados}

Para compor o corpus textual da análise foram selecionadas teses e dissertações do ano 2012 e 2017. A escolha se deu pelo aumento significativo de trabalhos, o ano de 2012 contou com 19 trabalhos, correspondendo a nove defesas de mestrado, cinco defesas de doutorado e cinco de profissionalização. Em 2017 o número de trabalho defendidos aumentou em 73,68\% em relação ao ano de 2012, correspondendo a 33 trabalhos defendidos, sendo 17 dissertações, 10 teses e seis mestrados profissional.

Em relação às instituições de ensino superior também houve um aumento. No ano de 2012 foram 13 instituições, com o predomínio da região sudeste. Já no ano de 2017 foram 18 instituições, com um aumento de defesas na região sul, nordeste e a inserção de defesas na área da HEM na região norte, como pode ser visto no Quadro 1.

\begin{tabular}{|c|l|c|c|}
\hline \multicolumn{1}{|c|}{ Região } & \multicolumn{1}{|c|}{ Instituição } & $\mathbf{2 0 1 2}$ & $\mathbf{2 0 1 7}$ \\
\hline \multirow{2}{*}{ Centro-oeste } & Universidade Federal de Mato Grosso (UFMT) & 1 & - \\
\cline { 2 - 4 } & Universidade Federal de Mato Grosso do Sul (UFMS) & 1 & 4 \\
\hline \multirow{2}{*}{ Nordeste } & Universidade Estadual de Santa Cruz (UESC) & - & 1 \\
\cline { 2 - 4 } & Universidade Federal da Bahia (UFBA) & 1 & 1 \\
\cline { 2 - 4 } & Universidade Federal do Rio Grande do Norte (UFRN) & - & 1 \\
\hline \multirow{2}{*}{ Norte } & Universidade do Estado do Amazonas (UEA) & - & 2 \\
\cline { 2 - 4 } & Universidade Federal do Pará (UFPA) & - & 1 \\
\hline \multirow{2}{*}{ Sudeste } & Pontifícia Universidade Católica Minas Gerais (PUCMG) & 1 & 2 \\
\cline { 2 - 4 } & Universidade Anhanguera de São Paulo (UNIAN) & 1 & - \\
\cline { 2 - 4 } & Universidade de São Paulo (USP) & & \\
\hline
\end{tabular}




\begin{tabular}{|c|c|c|c|}
\hline & Universidade Estadual de Campinas (UNICAMP) & - & 1 \\
\hline & $\begin{array}{l}\text { Universidade Estadual Paulista Júlio de Mesquita Filho } \\
\text { (UNESP/Bauru) }\end{array}$ & - & 3 \\
\hline & $\begin{array}{l}\text { Universidade Estadual Paulista Júlio de Mesquita Filho } \\
\text { (UNESP/Rio Claro) }\end{array}$ & 4 & 3 \\
\hline & Universidade Federal de Juiz de Fora (UFJF) & 1 & 2 \\
\hline & Universidade Federal de São Carlos (UFSCar) & 1 & - \\
\hline & Universidade Federal de São Paulo (UNIFESP) & - & 1 \\
\hline & Universidade Federal do Rio de Janeiro (UFRJ) & 1 & 1 \\
\hline & Universidade Severino Sombra (USS) & 3 & - \\
\hline \multirow[t]{6}{*}{ Sul } & Pontifícia Universidade Católica do Paraná (PUCPR) & 2 & 2 \\
\hline & Universidade Estadual de Ponta Grossa (UEPG) & 1 & - \\
\hline & Universidade Federal de Santa Catarina (UFSC) & - & 3 \\
\hline & Universidade Federal do Paraná (UFPR) & - & 2 \\
\hline & Universidade Federal do Rio Grande do Sul (UFRGS) & - & 2 \\
\hline & Universidade Regional de Blumenau (FURB) & 1 & - \\
\hline
\end{tabular}

Quadro 1. HEM - Instituições de Ensino Superior - 2012 e 2017 Fonte: elaborado pelos autores

Outro aspecto que podemos identificar um aumento e diversidade são para os Programas de Pós-Graduação, de cinco programas no ano de 2012 para 11 no ano de 2017, correspondendo um aumento de 120\%, conforme o Quadro 2.

\begin{tabular}{|l|c|c|}
\hline \multicolumn{1}{|c|}{ Nome do Programa de Pós-Graduação } & $\mathbf{2 0 1 2}$ & $\mathbf{2 0 1 7}$ \\
\hline Educação & 6 & 2 \\
\hline Educação Científica e Tecnológica & - & 3 \\
\hline Educação e Saúde na Infância e Adolescência & - & 1 \\
\hline Educação em Ciências e/em Matemática (s) & - & 5 \\
\hline Educação Matemática & 10 & 12 \\
\hline Educação para a Ciência & - & 3 \\
\hline Ensino & - & 1 \\
\hline Ensino de Ciências Naturais e Matemática & 1 & 1 \\
\hline Ensino de Matemática & 1 & 3 \\
\hline Ensino, Filosofia e História das Ciências & 1 & 1 \\
\hline Multiunidades em Ensino de Ciências e Matemática & - & 1 \\
\hline
\end{tabular}

Quadro 2. HEM - Programas de Pós-Graduação - 2012 e 2017 Fonte: elaborado pelos autores 
Esse crescimento nos Programas de Pós-Graduação se dá em âmbito nacional, conforme aponta a pesquisa realizada pela CAPES. "No Brasil, o Sistema Nacional da Pós-Graduação (SNPG) cresce de forma sustentável e contínua, atingindo o crescimento de $25 \%$ no número de programas nos últimos quatro anos - em dados absolutos o sistema avançou de 3.337 para 4.175 programas entre os anos de 2013 e 2016" (CAPES, 2017).

Em relação à busca dos trabalhos defendidos no ano de 2012 e 2017, apenas não foi possível encontrar o trabalho de Santos (2012). Foram selecionados os resumos para compor o corpus textual. Porém, cabe destacar, de acordo com Morais e Ambrósio (2007: 9), que a "preparação dos dados é a primeira etapa do processo de descoberta de conhecimento em textos. Envolve a seleção dos dados que constituem a base de textos de interesse e o trabalho inicial para tentar selecionar o núcleo que melhor expressa o conteúdo destes textos".

Para a inclusão dos dados no software é necessário a separação dos textos com linhas de comando, da seguinte maneira: digitar quatro asteriscos (sem espaço em branco antes deles), um espaço branco subsequente, um asterisco e o nome da variável (sem espaço em branco entre eles), neste caso Resumo, seguido do ano (2012 ou 2017), um traço embaixo da linha (underline) e finalmente, o número do trabalho. Por exemplo: ******Resumo2012_01.

Foram preparados dois corpus textuais, um referente aos resumos do ano de 2012 e outro para o ano de 2017. A seguir, apresentamos um exemplo de cada ano analisado:

\section{***** Resumo2012_01}

O tema do presente estudo é sobre a formação matemática dos futuros professores das séries iniciais do Ensino Fundamental. A pergunta norteadora do estudo é Como os formandos em Pedagogia de 3 universidades de Curitiba, se apropriaram, em sua formação inicial, dos conhecimentos indispensáveis à sua futura atuação como professores de Matemática nas séries iniciais do Ensino Fundamental?. A partir de uma perspectiva histórico_cultural de um tempo recente o estudo fundamentou_se em aportes teórico_metodológicos buscados em Certeau (1982); Chartier (1990); Chervel (1990); Julia (2001) e Viñao Frago (2001). Para a contextualização do objeto de estudo, foram consideradas contribuições de Brzezinski (2010); Saviani (1976, 1994, 2003, 2008 e 2009); Scheibe (2006). Em relação aos aspectos teóricos da formação do professor, relativamente aos saberes_profissionais nos reportamos principalmente a Tardif (2002). Como aportes da História_Educação_Matemática destacaram Valente (2007); Pinto (2011). 
As fontes foram constituídas com documentos oficiais como a Lei de Diretrizes e Bases 9394 de 1996, os Pareceres 5_2005 e 3_2006 do Conselho Nacional de Educação e os Parâmetros Curriculares Nacionais, PCNs (1997) e PCNs Matemática (1997). Os documentos escolares utilizados foram os Planos de Ensino das disciplinas responsáveis pela formação matemática mobilizada nos referidos cursos investigados. Para melhor compreender a apropriação dos elementos que marcaram a referida formação, foram aplicados questionários a 124 formandos em Pedagogia de 2011, das 3 Universidades investigadas, sendo 2 particulares e 1 pública, tendo em vista a obtenção de seus depoimentos pessoais. A pesquisa apontou que a maioria dos formandos não frequentou no Ensino Médio o curso normal ou magistério e que desenvolveram sua formação matemática para a docência das séries iniciais do Ensino Fundamental no curso de Pedagogia indicando assim a importância do curso para sua formação inicial. De acordo com as respostas dos formandos constatamos que há lacunas na formação dos professores pedagogos e que a apropriação dos conhecimentos matemáticos necessários ao magistério do Ensino Fundamental poderá ser mais consistente se houver um aumento da carga horária, possibilitando ao formando um suporte teórico_metodológico que lhe permita desenvolver adequadamente sua futura profissão.

\section{*****:Resumo2017_01}

A intenção desta pesquisa foi compreender e elaborar versões históricas, a partir de diversas perspectivas documentais e testemunhais, de como se deu a formação dos professores que ensinavam matemática no estado do RN, nas séries que correspondem aos atuais ensinos fundamental e médio, incluindo possíveis aspectos relacionados ao desenvolvimento desse processo de formação, antes e durante o período de criação dos 4 mais antigos cursos superiores que habilitavam professores em Matemática neste estado. Utilizamos como metodologia de pesquisa a história_oral, produzindo e analisando 20 narrativas e documentos acessados em arquivos públicos e privados. Seguindo uma perspectiva transdisciplinar, elaboramos compreensões sobre o processo, formação de professores de matemática, e constituímos narrativas segundo 3 disposições distintas mas interconectadas, a análise narrativa de narrativas, a análise de singularidades e a análise de convergências. $\mathrm{O}$ texto final desse movimento de pesquisa tem um estilo alternativo que pretende dialogar com as teorizações feitas. 
Recomenda-se que não se justifique o texto, não use negrito, nem itálico ou outro recurso semelhante. As palavras compostas hifenizadas quando digitadas com hífen são entendidas como duas palavras (o hífen vira espaço em branco), devem ser substituídos com um traço underline. Por exemplo, pré-requisito mudou para pré_requisito, assim como palavras que mesmo não possuindo hífen dão uma ideia de ligação ou são nomes próprios, como nos seguintes exemplos, história da educação matemática ficou história_educação_matemática, e Colégio Pedro II passou para Colégio_Pedro_II. Os números devem ser mantidos na forma de algarismos, não usar caracteres especiais como aspas (“), apóstrofo ('), hífen (-), cifrão (\$), porcentagem (\%), reticências (...), e nem asterisco (*), este último apenas como linha de comando.

A seguir apresentamos as diversas análises feitas com o software IRaMuTeQ a respeito das comparações entre a produção de teses e dissertações no ano de 2012 e 2017, desde a frequência de palavras até novos temas de pesquisas dentro do período.

\section{Resultados e discussóes}

A primeira opção de análise que o IRaMuTeQ disponibiliza está relacionado aos dados estatísticos do corpus textual, fornecendo o número de textos e segmentos de textos, ocorrências, frequência média das palavras, bem como a frequência total de cada forma e sua classificação gramatical.

O resultado da análise de estatísticas textuais, traz cinco informações que resumem o corpus textual como segue.

a) Número de textos: é o número de textos (registros) contidos no corpus. Neste caso, por exemplo, o corpus que corresponde ao ano de 2012 possui 18 textos (sendo que uma dissertação em nível de profissionalização não consta na análise, pois não foi possível encontrar o resumo do trabalho), e o ano de 2017 possui 33 textos, correspondendo aos resumos das teses e dissertações;

b) Número de ocorrências: é o número total de palavras contidas no corpus;

c) Número de formas: são as palavras consideradas ativas (adjetivos, nomes, verbos) e suplementares (artigos e pronomes). Foram eliminados os advérbios, as conjunções, onomatopéias e as preposições;

d) Número de hapax: são palavras que aparecem apenas uma vez em todo o corpus;

e) Média de ocorrências por texto: é o número de ocorrências dividido pelo número de textos (Salviati, 2017: 33-34). 
Podemos observar os resumos das análises de estatísticas textuais no Quadro 3 e Quadro 4.

\begin{tabular}{|c|c|}
\hline \multicolumn{2}{|c|}{ Resumo } \\
\hline Número de textos & 18 \\
\hline Número de ocorrências & 5373 \\
\hline Número de formas & 1246 \\
\hline Número de hapax & 688 \\
& $12.80 \%$ de ocorrências \\
& $55.22 \%$ de formas \\
\hline Média de ocorrências por texto & 298.50 \\
\hline
\end{tabular}

Quadro 3. Resumo corpus textual 2012

Fonte: resumo estatístico gerado pelo software IRaMuTeQ

\begin{tabular}{|c|c|}
\hline \multicolumn{2}{|c|}{ Resumo } \\
\hline Número de textos & 33 \\
\hline Número de ocorrências & 8153 \\
\hline Número de formas & 1487 \\
\hline Número de hapax & 738 \\
& $9.05 \%$ de ocorrências \\
& $49.63 \%$ de formas \\
\hline Média de ocorrências por texto & 247.06 \\
\hline
\end{tabular}

Quadro 4. Resumo corpus textual 2017

Fonte: resumo estatístico gerado pelo software IRaMuTeQ

O número de textos do corpus dos resumos das teses e dissertações do ano de 2012 (Quadro 3) corresponde a 18 textos. O número total de palavras foi de 5373, o número de formas 1246 e as palavras hapax 688. Em relação ao ano de 2017 (Quadro 4) corresponde a 33 textos, o número total de palavras 8153, formas 1487 e 738 hapax.

Utilizamos para a visualização dos corpus textuais do ano de 2012 e 2017 a nuvem de palavras, em razão de agrupar e organizar as palavras pela frequência. Nos resumos das produções do ano de 2012 podemos observar que as palavras de maior frequência são: ensino (70), matemática (60), pesquisa (39), professor (31), história (27), estudo (23), análise (22), período (21), curso (20), formação (19), livros didáticos e história da educação matemática (18), como está representado na Figura 2. 


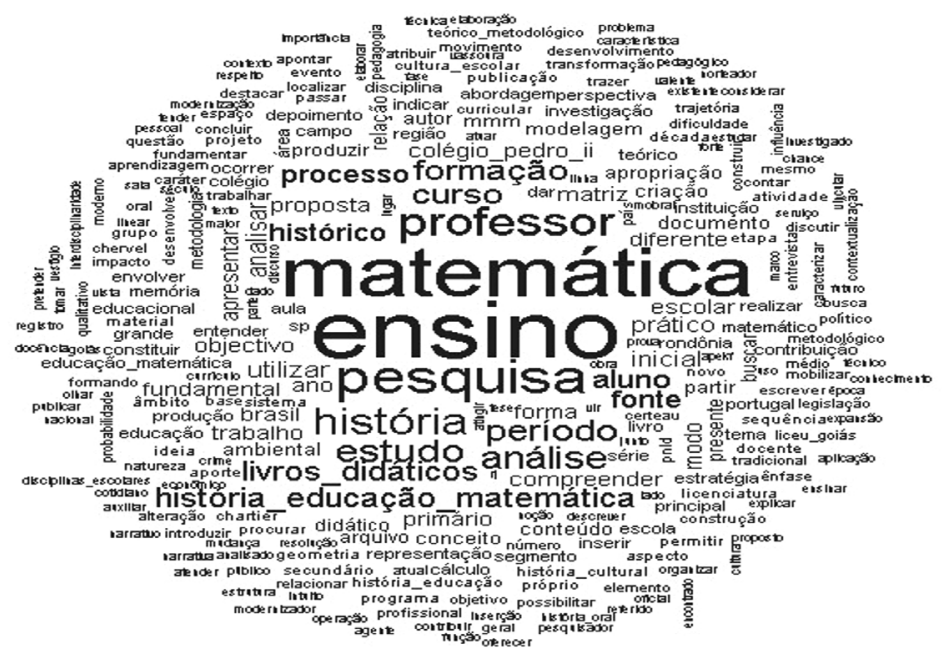

Figura 2. Nuvem de palavras corpus textual 2012

Fonte: elaborado pelos autores a partir do software IRaMuTeQ

Em relação à contagem das palavras-chave das teses e dissertações que se destacam nas pesquisas do ano de 2012 são: história da educação matemática (11), formação de professores e educação matemática (3), história oral e ensino de matemática (2). A partir da frequência das palavras, representada pela Figura 2, podemos identificar as temáticas e metodologias das pesquisas. Como resultado temos a HEM sendo a área de investigação principal para as pesquisas. Nos trabalhos, como teses e dissertações, os documentos selecionados, operacionalizados e interrogados se transformam em fontes de pesquisa. Segundo Luca (2012) os documentos históricos são vestígios do passado que se transformam em fontes históricas pela mobilização realizada pelo historiador no decorrer da pesquisa. Podemos observar que foram mobilizados livros didáticos em sua maioria e o interesse está relacionado a formação de professores que ensinam matemática.

As palavras de maior frequência do corpus textual dos resumos das teses e dissertações do ano de 2017 são: ensino e pesquisa (75), professor (74), matemática (63), formação (47), estudo (35), período (33), análise (32), histórico (30), as palavras curso, ano e primário (28), fonte e partir (27), objectivo (26), história (24), as palavras compreender, trabalho e autor (22), aritmética (21), programa e metodologia (20), livros didáticos, ensinar e década (18), forma e história da educação matemática (17), como pode ser observado na Figura 3. 


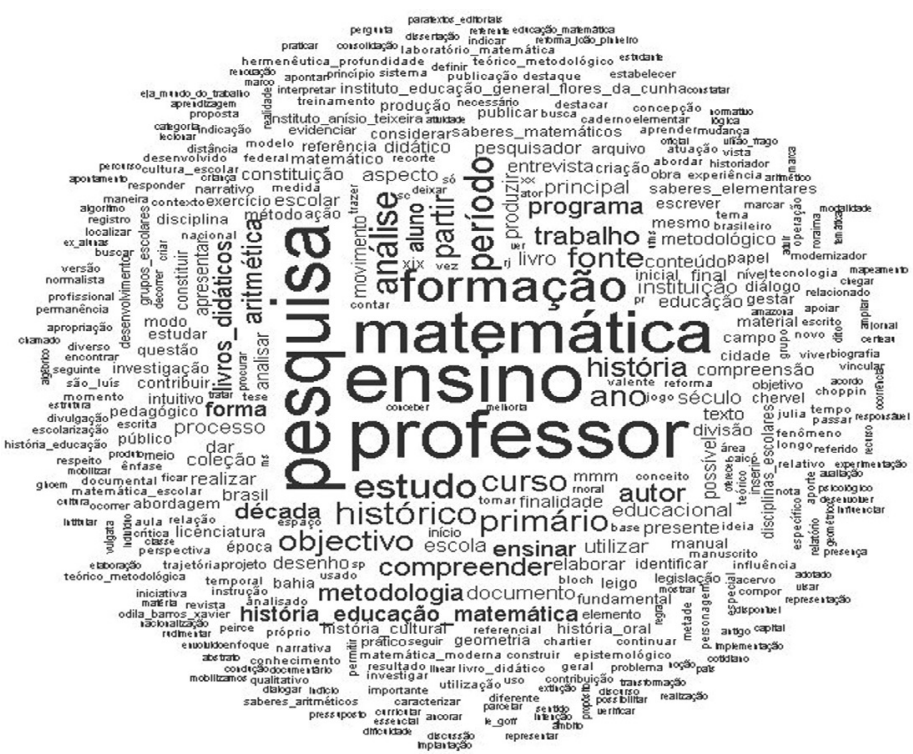

Figura 3. Nuvem de palavras corpus textual 2017

Fonte: elaborado pelos autores a partir do software IRaMuTeQ

Em relação à contagem das palavras-chave das pesquisas do ano de 2017 correspondem a seguinte frequência: história da educação matemática (24), história oral (7), educação matemática (6), livro didático e formação de professores (5), aritmética (4), hermenêutica de profundidade (3), saberes matemáticos e saberes elementares matemáticos (2). O que podemos verificar em comparação com o ano de 2012 são novas temáticas e metodologias de pesquisa, uma delas são pesquisas relacionadas aos saberes elementares e matemáticos, e a hermenêutica de profundidade.

É importante destacar que até o momento foi realizada a análise estatística dos corpus textuais, relacionado a quantidade de palavras e a frequência das mesmas. Assim, Morais e Ambrósio (2007: 6) destacam "Ao utilizar os recursos de mineração de textos, um usuário não solicita exatamente uma busca, mas sim uma análise de um documento. Entretanto, este não recupera o conhecimento em si. É importante que o resultado da consulta seja analisado e contextualizado para posterior descoberta de conhecimento".

Desta forma, dando continuidade às análises, utilizamos um outro recurso que o IRaMuTeQ proporciona, a análise fatorial de correspondência (AFC), uma representação gráfica em plano cartesiano, que auxilia a visualização das proximidades e distanciamentos entre os trabalhos a partir do cruzamento do vocabulário do corpus textual. 
A Análise Fatorial de Correspondência é uma representação gráfica dos dados para ajudar a visualização da proximidade entre classes ou palavras. Os procedimentos executados nesta análise englobam o cálculo das frequências e os valores de correlação qui-quadrado de cada palavra do corpus, a partir da frequência pré-definida; e a execução da análise fatorial de correspondências (AFC) numa tabela de contingência que cruza as formas ativas e as variáveis. (Salviati, 2017:39)

A Figura 4 mostra o plano cartesiano do corpus textual do ano de 2012, representando os 18 resumos das teses e dissertações que mais possuem proximidades e distanciamentos entre si (Anexo).

Os trabalhos se concentram entre o eixo vertical (-0.5 a 0.5$)$ e o eixo horizontal (-0.5 a 0.5). Podemos observar que o Resumo2012_19, uma dissertação da FURB é o mais distante dos demais trabalhos, está no eixo vertical positivo (entre 1.5 e 2.0) e no eixo horizontal negativo (entre -0.5 e 0.0 ). A pesquisa possui como palavras-chave ensino de matemática; probabilidade; acaso e; sequência didática. A investigação principal do trabalho está pautada na aprendizagem do aluno, na elaboração e aplicação de uma sequência didática. Isto é, a pesquisa se distancia das demais, pois, não possui as características das pesquisas que investigam a HEM.

Em relação à Figura 4, podemos perceber uma sobreposição de trabalhos no cruzamento dos eixos vertical e horizontal, entre eles uma dissertação da UNESP/Rio Claro (Resumo2012_04) correspondendo aos estudos relacionados a etnomatemática; uma dissertação da UFMS (Resumo2012_06) o qual trabalha com uma perspectiva teórico-metodológica para pesquisa na área da HEM; e uma tese da UFBA (Resumo2012_12) que busca analisar as memórias dos ex-alunos a partir de entrevistas. São três trabalhos distintos entre si, em relação às teorias e metodologias mobilizadas para pesquisa.

A análise do corpus textual dos resumos de teses e dissertações do ano de 2017 corresponde a 33 textos que possuem proximidades e distanciamentos entre si. Os trabalhos estão mais dispersos do que no ano anterior analisado, como é possível verificar na Figura 5.

No entanto podemos identificar dois grupos de trabalhos, o primeiro está no eixo vertical positivo (entre 0 e 1 ) e no eixo horizontal negativo (entre -1 e 0), correspondendo a seis trabalhos: quatro dissertações das seguintes instituições UFJF (Resumo2017_09), UFSC (Resumo2017_13), UFPA (Resumo2017_19), PUCPR (Resumo2017_29); e duas teses, uma da UNIAN (Resumo2017_11) e outra da UNIFESP (Resumo2017_33). Os trabalhos se aproximam em relação ao referencial teórico e as metodologias, sendo pesquisas que trabalham com uma perspectiva da História Cultural, e analisam os "saberes", tanto elementares quanto matemáticos. 


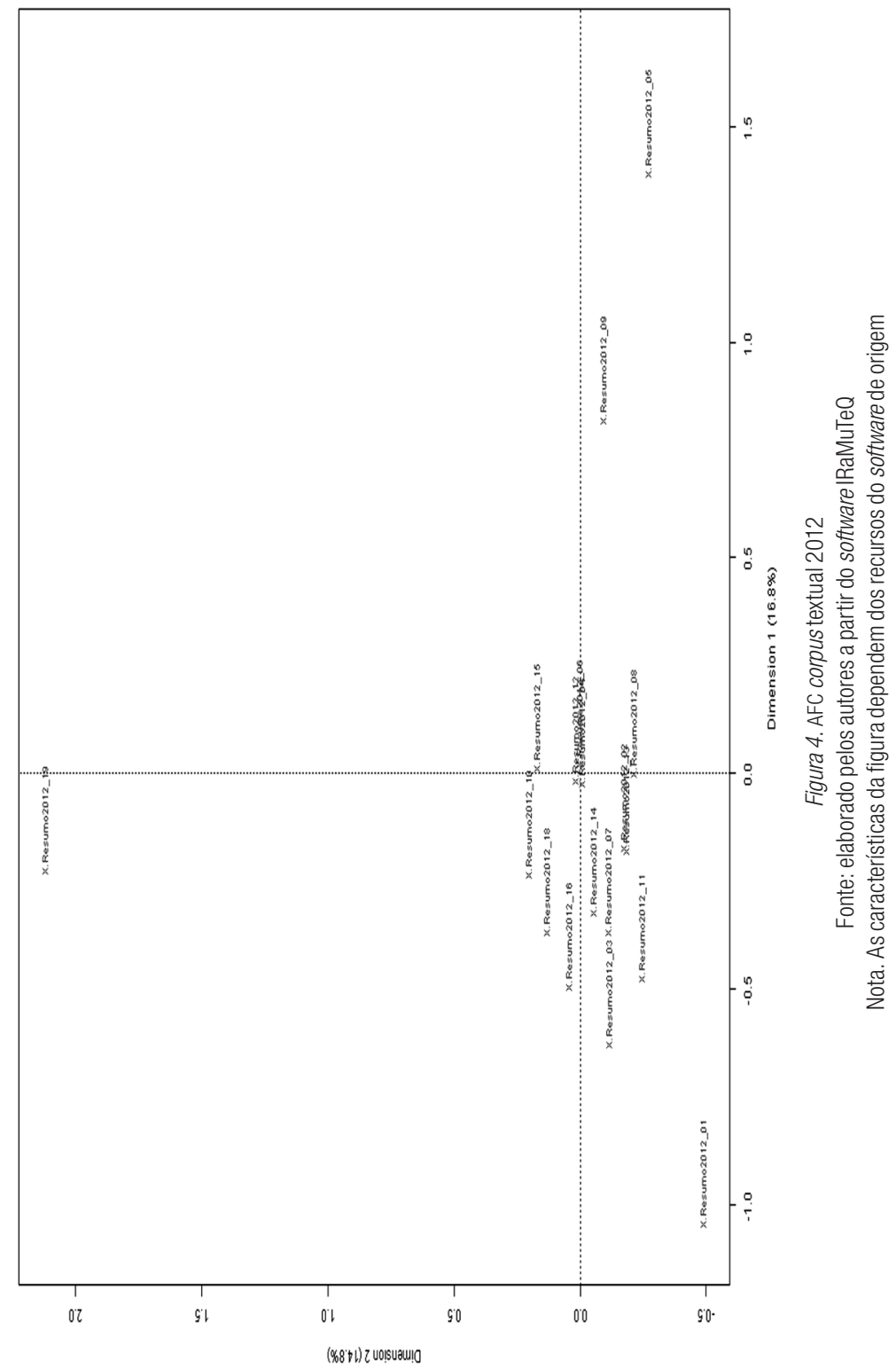


ANÁLISE TEXTUAL COM IRAMUTTEQ DE PESQUISAS RECENTES...

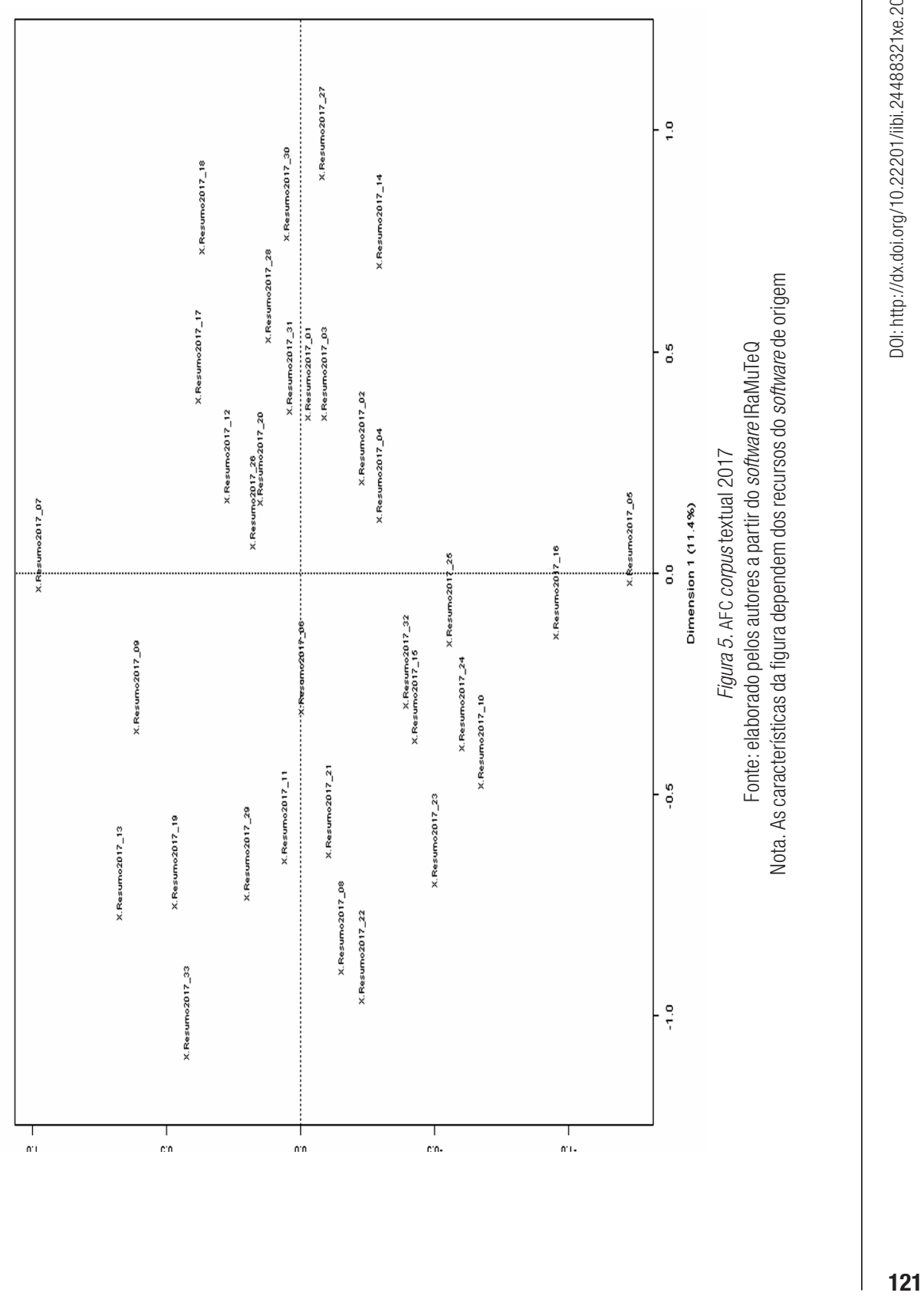


As pesquisas relacionam-se ao Grupo de Pesquisa de História da Educação Matemática no Brasil (GHEMAT, https://www.ghemat-brasil.com/), em específico com o Projeto de Pesquisa "A Constituição dos Saberes Elementares Matemáticos: a Aritmética, a Geometria e o Desenho no curso primário em perspectiva histórico-comparativa, 1890-1970".

Este projeto reúne pesquisadores doutores de dez estados brasileiros com o fim de elaboração de uma investigação histórico-comparativa. A temática de estudo refere-se à análise da trajetória de constituição dos saberes elementares matemáticos (a Aritmética, a Geometria e o Desenho) presentes no curso primário de diferentes regiões brasileiras desde o período de criação do modelo "grupo escolar" até a sua extinção a partir da criação da escola obrigatória de oito anos. Este projeto nutre-se de experiência anterior obtida com o desenvolvimento de estudos histórico-comparativos entre Brasil e Portugal e apoio da CAPES e do GRICES (2006-2010), e busca consolidar uma rede nacional de pesquisadores interessados na produção de uma história glocal da educação matemática. A pesquisa orienta-se pelas seguintes questões: Que trajetórias de constituição tiveram a Aritmética, a Geometria e o Desenho para os primeiros anos escolares? Ou, dizendo de outro modo: como foram organizados/reorganizados os saberes elementares matemáticos para estarem presentes na escola graduada? Como o modelo "grupo escolar”, difundido a partir de São Paulo, constituiu/reconstituiu saberes elementares matemáticos em diferentes pontos do Brasil? (GHEMAT, s. a.)

O segundo grupo de trabalhos estão no eixo vertical negativo (entre -1 e 0 ) e o eixo horizontal positivo (entre 0 e 1 ), correspondendo a seis trabalhos: quatro dissertações, entre elas duas pela UNESP (Resumo2017_03) e (Resumo2017_04), uma pela UFPR (Resumo2017_14) e outra da UFMS (Resumo2017_27); e duas teses também pela UNESP (Resumo2017_01) e (Resumo2017_02). A singularidade desses trabalhos, suas aproximações estão relacionadas às pesquisas da História Oral, em específico relacionadas ao Grupo de História Oral e Educação Matemática (GHOEM, s. a.).

Outro aspecto que identificamos na contagem das palavras-chave das teses e dissertações e apresentam novas temáticas, como os "saberes" matemáticos e/ou elementares, que mencionamos anteriormente, há também novas temáticas relacionadas ao referencial metodológico da "Hermenêutica de Profundidade", que faz parte do Projeto de Pesquisa do GHOEM intitulado "Hermenêutica de Profundidade - Análise de livros antigos e outras fontes relativas à Cultura Matemática Escolar”. 
O GHOEM constituiu um acervo, hoje com mais de 1500 títulos originais, de livros antigos (didáticos de Matemática e de referência para a Educação Matemática) visando a ampliar sua atuação no que diz respeito à História da Educação Matemática Brasileira. A partir desse acervo, são desenvolvidos estudos envolvendo a análise de livros antigos segundo a perspectiva da Hermenêutica de Profundidade (de John Thompson), vinculada à noção de Paratexto (de Genette). Ampliando as fontes e abordagens próprias à História Oral, já familiares ao Grupo que mantém essa linha de pesquisa, pretende-se abordar outras faces da cultura escolar. (GHOEM, s. a.)

Podemos dizer que esses dois grupos realizam trabalhos que investigam a HEM, porém utilizam diferentes recursos teóricos e metodológicos, contribuindo para um enriquecimento da área, com novas temáticas e problemas de pesquisas a serem investigados.

Ao realizar a AFC, buscamos avançar nas análises, e evitar a crítica realizada por Morais e Ambrósio (2007: 26), ao mencionar que "um dos principais problemas da área é a falta de técnicas efetivas de análise semântica de textos. Observa-se vários trabalhos que implementam análises estatísticas, entretanto, pouco se evoluiu em termos de semântica”. Desta forma, apresentamos distanciamentos e aproximações entre os trabalhos analisados, em particular suas propostas teóricas e o lugar de fala, como, por exemplo, os grupos de pesquisas.

\section{Considerações finais}

Buscamos neste artigo trazer uma abordagem da Humanidades Digitais, a qual dialoga com a área das humanidades, das ciências exatas e tecnológicas. Utilizamos a produção da área da História da educação matemática (HEM) para compor o corpus textual de análise, assim como utilizamos como instrumentalização para a análise o software IRaMuTeQ.

Assim, ao refletirmos sobre as atividades de mediação no contexto contemporâneo dos fluxos tecnoculturais, não procuramos fazer uma apologia ao mundo digital e às TICs, mas de fazer constar que sua presença, mesmo que problemática, enriquece e disponibiliza novos meios e recursos para a apropriação das informações e conhecimentos, assim como para a expressão e criação cultural, dinamizando as relações sociais. (Almeida e Damian, 2015: 17)

Corroborando Almeida e Damian (2015: 17), as Humanidades Digitais estão em um território interdisciplinar de mediações às reflexões e práticas decorrentes das tecnologias na sociedade, quanto "a circulação e a apropriação do 
conhecimento, e o papel social que pode ser desempenhado pelas universidades e pelos pesquisadores nesse processo".

Para compor o corpus textual da análise, foram selecionadas as defesas dos anos de 2012, correspondendo a 18 trabalhos, e do ano de 2017 com 33 trabalhos. O IRaMuTeQ contribui para o processamento de dados, possibilitando o aprimoramento das análises textuais, integrando dados quantitativos e qualitativos na análise, resultando em maior objetividade e avanços às interpretações dos dados de texto.

Verificamos um aumento de novas temáticas e referenciais metodológicos em relação às defesas de teses e dissertações do ano de 2012 para 2017, em específico as pesquisas vinculadas aos grupos de pesquisa GHEMAT e GHOEM, contribuindo para novas temáticas, referenciais e metodologias de pesquisa. Portanto, se evidencia a influência de grupos de pesquisa nas agendas de pesquisa das universidades.

No entanto, é importante destacar que o IRaMuTeQ foi utilizado como um recurso metodológico, que contribui para uma pré análise do objeto a ser investigado, neste caso as teses e dissertações defendidas em 2012 e 2017. De acordo com Camargo e Justo (2018: 517) "os relatórios gerados pelo software não são, em si, a análise dos dados" cabe ao pesquisador fazê-las. O software transformou dados qualitativos em quantitativos, possui diversos recursos que auxilia o pesquisador na descoberta de novos conhecimentos.

Os resultados demonstram a utilidade das ferramentas de Humanidades Digitais, especificamente aquelas relacionadas à mineração de texto para a análise da evolução da produção de conhecimento na área da HEM.

\section{REFERÊNCIAS}

Alves, Daniel. 2016. "As Humanidades Digitais como uma comunidade de práticas dentro do formalismo académico: dos exemplos internacionais ao caso português". Ler História 69. https://doi.org/10.4000/lerhistoria.2496

Almeida, Marco Antonio de e Ieda Pelógia Martins Damian. 2015. "Humanidades digitais: um campo praxiológico para mediações e políticas culturais?”. Trabalho apresentado no 16th Encontro Nacional de Pesquisa em Ciência da Informação, João Pessoa, 26-30 de outubro.

Brito, Arlete J. e Maria Ângela Miorim. 2016. "A institucionalização da História da Educação Matemática”, en Pesquisa em História da Educação Matemática no Brasil, editado por Antonio V. M. Garnica, 67-92. São Paulo: Livraria da Física.

Camargo, Brigido Vizeu e Ana Maria Justo. 2013. "IRAMUTEQ: um software gratuito para análisede dados textuais”. Temas em Psicologia 21 (2): 513-518. https://doi.org/10.9788/TP2013.2-16 
Camargo, Brigido Vizeu e Ana Maria Justo. 2018. "IRAMUTEQ: Tutorial para uso do software de análise textual IRAMUTEQ”. Florianópolis: Laboratório de Psicologia Social da Comunicação e Cognição; LACCOS, Universidade Federal de Santa Catarina.

CAPES (Coordenação de Aperfeiçoamento de Pessoal de Nível Superior). 2017. Avaliação da CAPES aponta crescimento da pós-graduação brasileira. Acesso em: 22 jan. 2019.

http://www.capes.gov.br/sala-de-imprensa/noticias/8558-avaliacao-d -capes-aponta-crescimento-da-pos-graduacao-brasileira

Coppe, Cristiane, Cláudia Regina Flores, Daniel Clark Orey e Maria Cristina Araújo de Oliveira. 2018. "History of Mathematics and Culture: Moments and Movements in Brazilian Mathematics Education", in Mathematics Education in Brazil Panorama of Current Research, Alessandro Jacques Ribeiro, Lulu Healy, Rute Elizabeted e Souza Rosa Borba e Solange Hassan Ahmad Ali Fernandes (org.), 1-278. Switzerland: Springer.

Dassie, Bruno Alves e David Antonio da Costa. 2018. História da Educação Matemática e Formação de Professores. São Paulo: Editora Livraria da Física.

Feldman, Ronen e Ido Dagan. 1995. "Knowledge discovery in textual databases (KDT)". Trabalho apresentado na 1th International Conference on Knowledge Discovery and Data Mining (KDD'95), Montréal, 20-21 de agosto.

Fleck, Ludwik. (1935) 2010. Gênese e Desenvolvimento de um Fato Científico: introdução à doutrina do estilo de pensamento e do coletivo de pensamento. Belo Horizonte: Fabrefactum.

Garnica, Antonio Vicente Marafioti. 2016. Pesquisa em História da Educação Matemática no Brasil: sob o signo da pluralidade. São Paulo: Editora da Física.

GHEMAT (Grupo de Pesquisa de História da Educaçao Matemática no Brasil). S. a. A constituição dos saberes elementares matemáticos: a aritmética, a geometria e o desenbo no curso primário em perspectiva histórico-comparativa, 1890-1970. Projeto de pesquisa coordenado por Wagner Rodriguez Valente. Acesso em: 20 jan. 2019. http://www2.unifesp.br/centros/ghemat/paginas/projeto_CONSTITUICAO Saberes.htm

GHOEM (Grupo de História Oral e Educação Matemática). S. a. Um pouco sobre nossa história. Acesso em: 20 jan. 2019. http://www2.fc.unesp.br/ghoem/

Luca, Tania Regina. 2012. "Notas sobre os historiadores e suas fontes”. Revista Eletrônica Métis. História e Cultura 11 (21): 13-21.

Morais, Edison Andrade Martins e Ana Paula L. Ambrósio. 2007. Mineração de textos. Relatório Técnico, RT- INF 005- 07. Goiás: Instituto de Informática da Universidade Federal de Goiás.

Oliveira, Maria Cristina Araújo de e Antonio Vicente Marafioti Garnica. 2018. "Relatório do GT 15 - História da educação matemática”, in: Relatório VII SIPEM, . Seminário Internacional de Pesquisa em Educação Matemática (Foz do Iguaçu, Paraná, 4 a 8 de novembro de 2018), 155-164. Brasil: SBEM (Sociedade Brasileira de Educação Matemática). Acesso em: 20 jan. 2019. http://www.sbembrasil.org.br/files/relatorio_viisipem.pdf

Ribeiro, Alessandro Jacques, Lulu Healy, Rute Elizabeted e Souza Rosa Borba e Solange Hassan Ahmad Ali Fernandes, org. 2018. Mathematics Education in Brazil Panorama of Current Research. Switzerland: Springer. 
Salviati, Maria Elisabeth. 2017. Manual do Aplicativo Iramuteq (versão 0.7 Alpha 2 e R Versão 3.2.3). Compilação, organização e notas de Maria Elisabeth Salviati. Acesso em: 10 nov. 2018.

http://iramuteq.org/documentation

/fichiers/manual-do-aplicativo-iramuteq-par-maria-elisabeth-salviati

Santos, Marlucia de Macedo. 2012. "Mapeando a evolução do pensamento geométrico por meio do software KSEG”. Dissertaçao, Profissionalização de Educação Matemática, Universidade Severino Sombra, Instituição de Ensino.

Valente, Wagner Rodrigues. 2014. História da Educação Matemática no Brasil. São Paulo: Editora Livraria da Física.

Para citar este texto:

Hoffmann, Yohana Taise, Edgar Bisset Alvarez y Yohannis Martí-Lahera. 2020. "Análise textual com IRaMuTeQ de pesquisas recentes em História da educação matemática no Brasil: um exemplo de Humanidades Digitais”. Investigación Bibliotecológica: archivonomía, bibliotecología e información 34 (84): 103-133.

http://dx.doi.org/10.22201/iibi.24488321xe.2020.84.58097 
ANÁLISE TEXTUAL COM IRAMUTEQ DE PESQUISAS RECENTES...

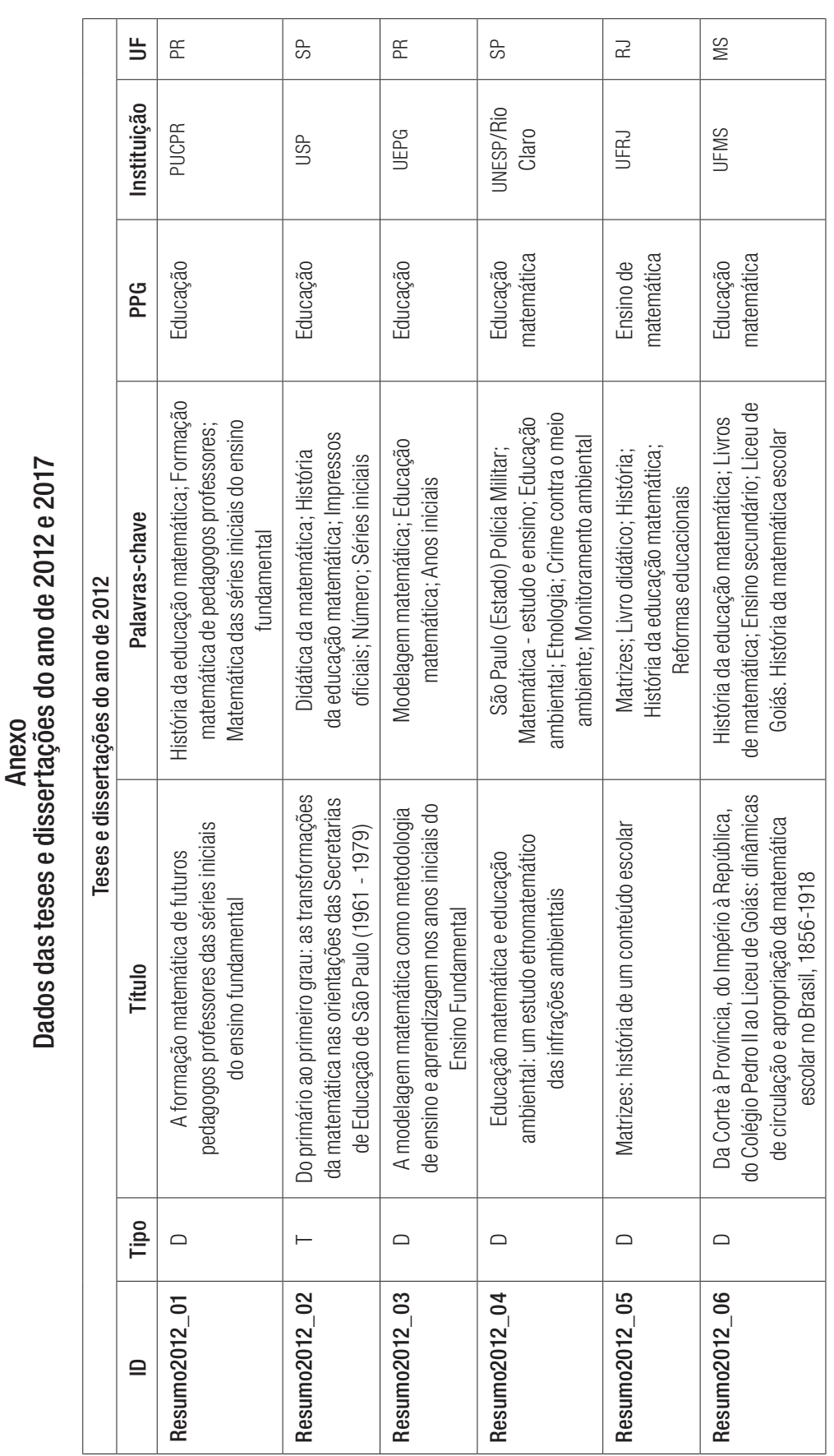

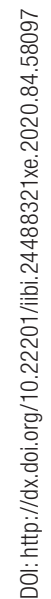




\begin{tabular}{|c|c|c|c|c|c|c|c|}
\hline के & $\stackrel{ }{\alpha}$ & के & $\stackrel{\Gamma}{\Sigma}$ & के & $\stackrel{\nwarrow}{\infty}$ & $\stackrel{E}{\Sigma}$ & के \\
\hline 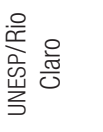 & $\begin{array}{l}\text { 웜 } \\
\text { 몸 }\end{array}$ & $\begin{array}{l}\text { 苟 } \\
\text { 岁 }\end{array}$ & $\begin{array}{l}\text { 岁 } \\
\stackrel{3}{3}\end{array}$ & $\underset{\vdots}{\grave{3}}$ & $\begin{array}{l}\text { 畐 } \\
\text { 足 }\end{array}$ & $\sum_{\text {站 }}^{E}$ & 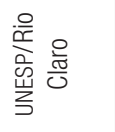 \\
\hline 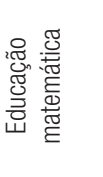 & 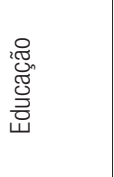 & 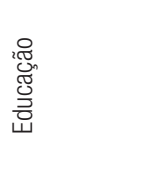 & 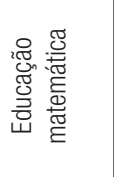 & 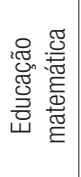 & 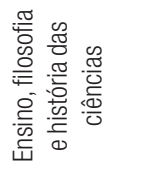 & 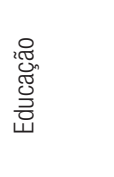 & 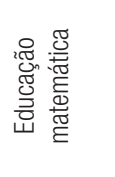 \\
\hline 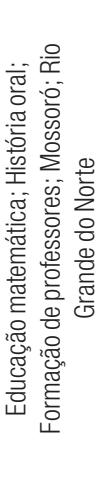 & 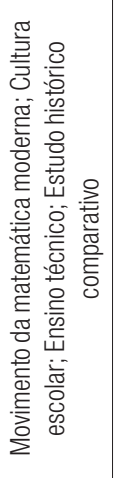 & 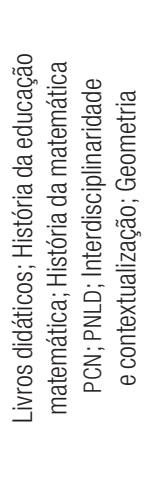 & 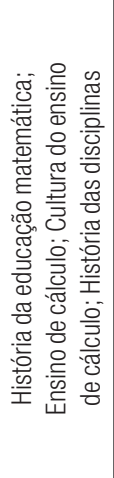 & 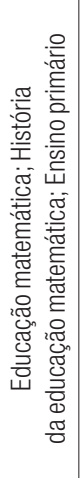 & 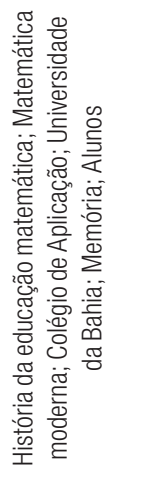 & 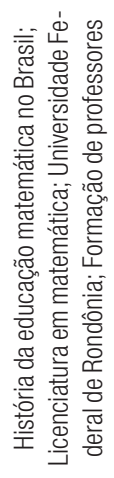 & 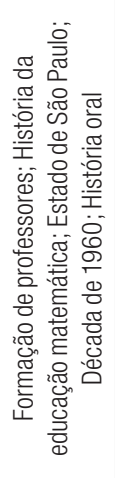 \\
\hline 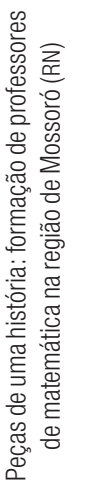 & 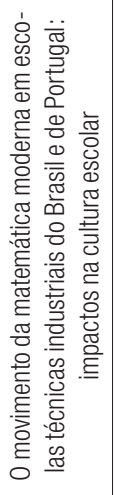 & 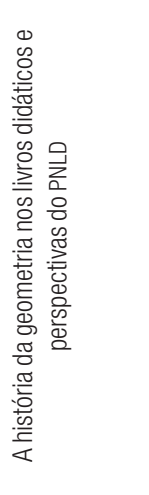 & 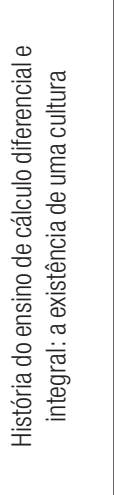 & 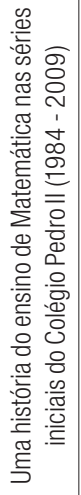 & 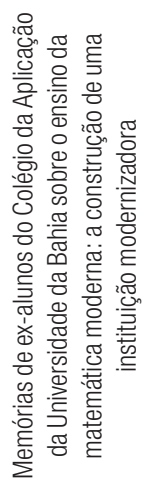 & 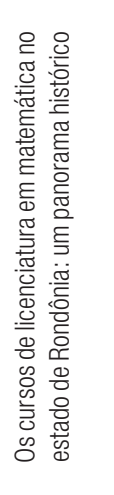 & 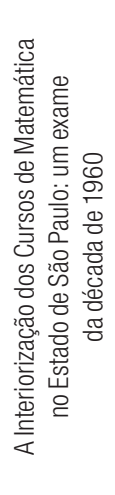 \\
\hline ○ & $\vdash$ & 口 & ○ & $\vdash$ & $\vdash$ & ○ & $\vdash$ \\
\hline 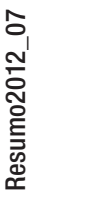 & 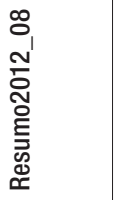 & 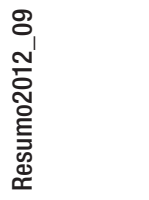 & 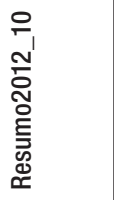 & 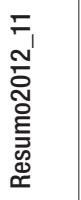 & 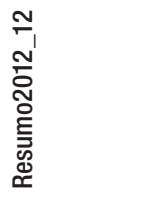 & 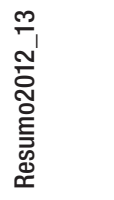 & 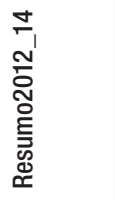 \\
\hline
\end{tabular}




\begin{tabular}{|c|c|c|c|c|c|c|c|c|c|c|}
\hline ฉ & $\vec{\propto}$ & $\vec{\propto}$ & के & U & & 岂 & के & के & के & के \\
\hline$\stackrel{\mathscr{D}}{\mathscr{S}}$ & $\stackrel{\mathscr{D}}{\mathscr{S}}$ & $\stackrel{\mathscr{D}}{\mathscr{S}}$ & 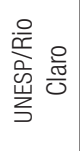 & 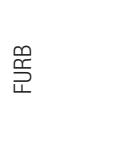 & & 怘 & 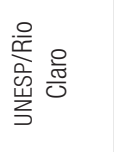 & 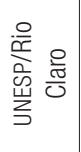 & 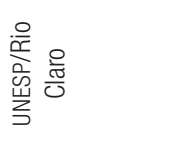 & 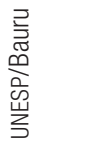 \\
\hline 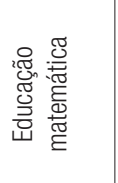 & 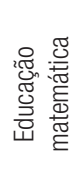 & 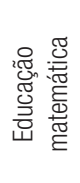 & 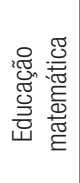 & 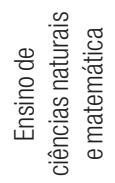 & & ఏ & 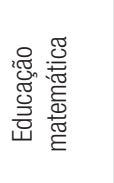 & 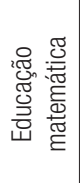 & 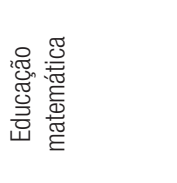 & 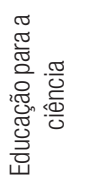 \\
\hline 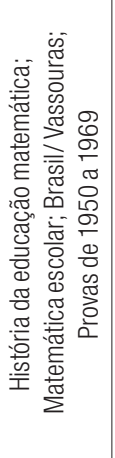 & 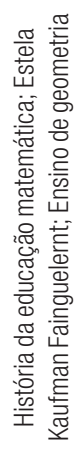 & 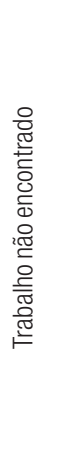 & 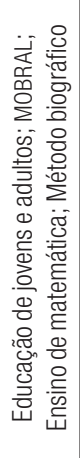 & 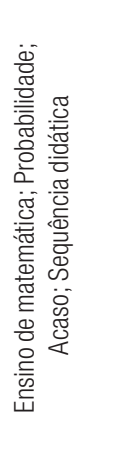 & 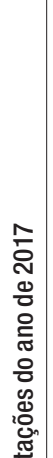 & 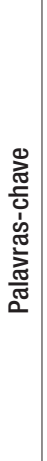 & 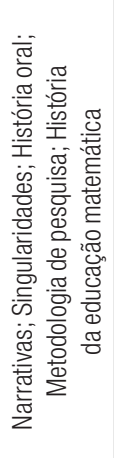 & 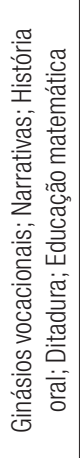 & 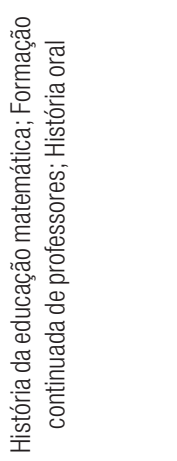 & 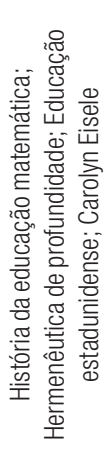 \\
\hline 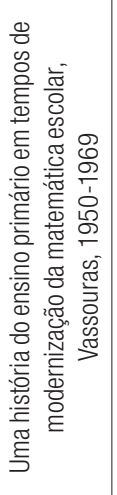 & 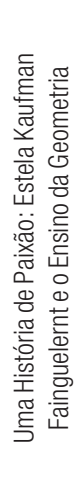 & 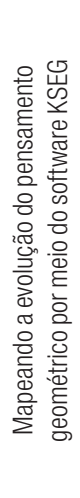 & 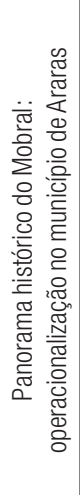 & 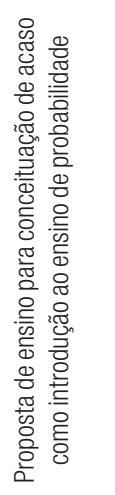 & 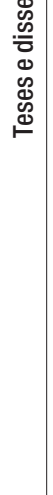 & 只 & 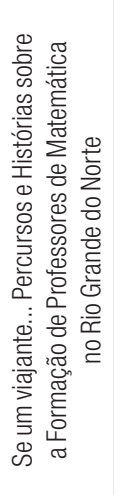 & 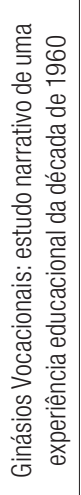 & 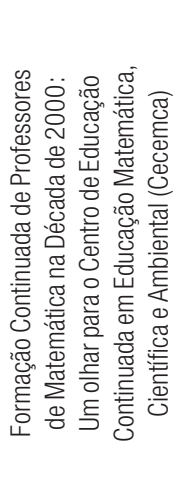 & 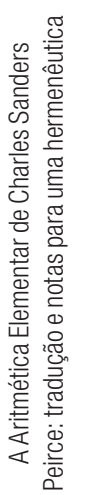 \\
\hline 口 & 口 & 口 & 口 & 口 & & $i$ 을 & $\vdash$ & $\vdash$ & 0 & 口 \\
\hline 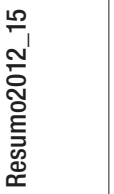 & 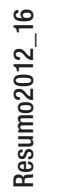 & 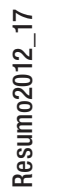 & 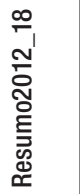 & 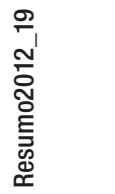 & & ㅇ & 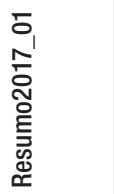 & 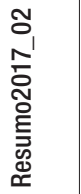 & 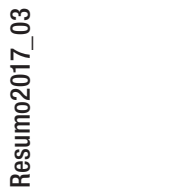 & 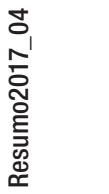 \\
\hline
\end{tabular}




\begin{tabular}{|c|c|c|c|c|c|c|c|}
\hline के & $\sum_{<}$ & $\stackrel{\Upsilon 2}{\alpha}$ & $\dddot{q}$ & $\sum^{0}$ & के & के & $\sum$ \\
\hline 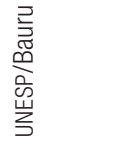 & 岁 & $\begin{array}{l}\text { 䍃 } \\
\text { 资 }\end{array}$ & $\begin{array}{l}\text { 鸽 } \\
\mathrm{a}\end{array}$ & 竺 & 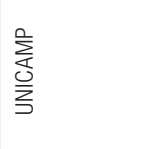 & 京 & 岁 \\
\hline 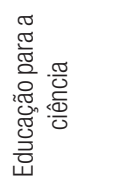 & 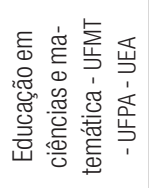 & 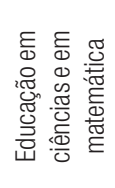 & 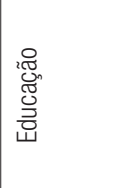 & 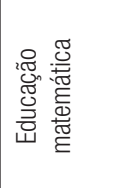 & 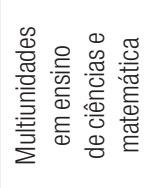 & 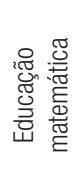 & 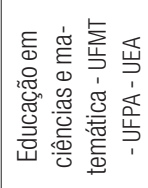 \\
\hline 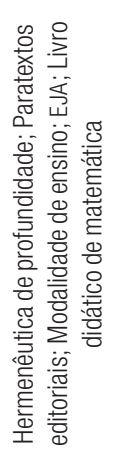 & 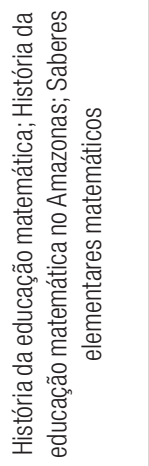 & 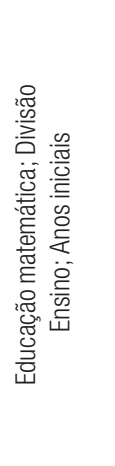 & 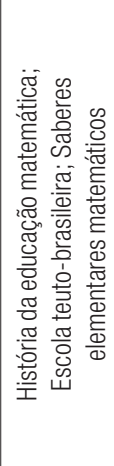 & 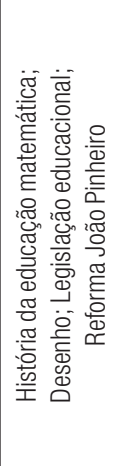 & 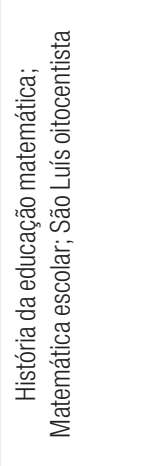 & 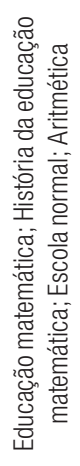 & 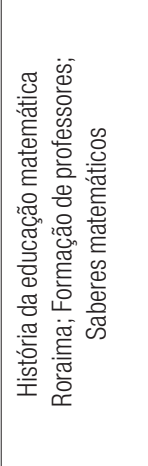 \\
\hline 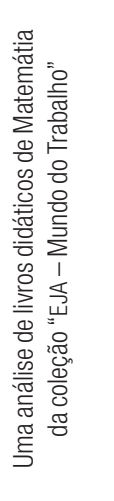 & 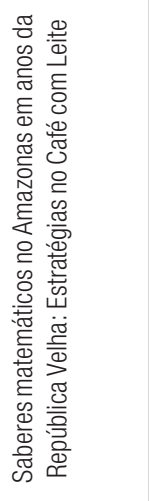 & 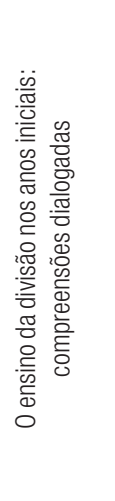 & 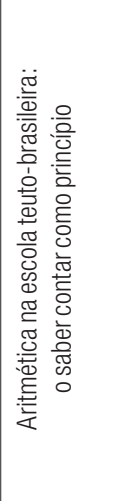 & 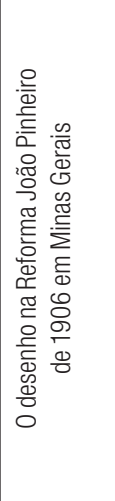 & 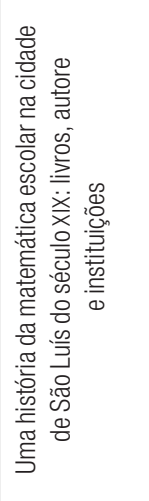 & 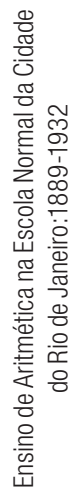 & 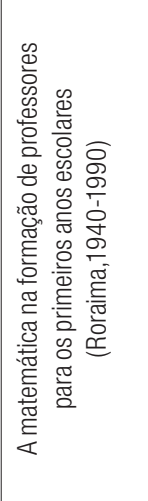 \\
\hline ○ & $\vdash$ & 0 & $\vdash$ & 0 & $\vdash$ & $\vdash$ & $\vdash$ \\
\hline 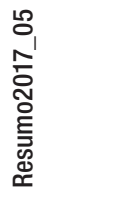 & 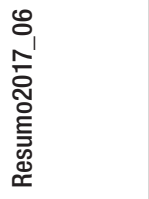 & 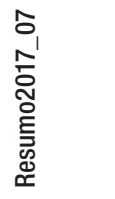 & 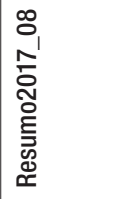 & 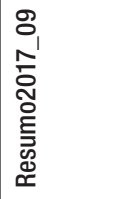 & 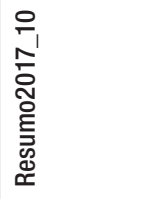 & 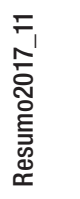 & 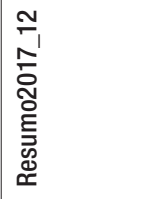 \\
\hline
\end{tabular}


ANÁLISE TEXTUAL COM IRAMUTTEQ DE PESQUISAS RECENTES...

\begin{tabular}{|c|c|c|c|c|c|c|c|c|}
\hline U & $\stackrel{\Upsilon}{\alpha}$ & $\mathcal{O}$ & 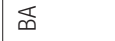 & $\underset{\infty}{\infty}$ & के & $\overleftarrow{a}$ & 占 & D \\
\hline $\begin{array}{l}0 \\
\text { U }\end{array}$ & $\begin{array}{l}\frac{a r}{2} \\
\text { 荺 }\end{array}$ & $\begin{array}{l}\text { U } \\
\text { J }\end{array}$ & 总 & 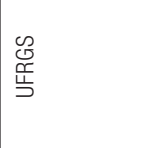 & 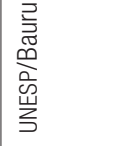 & 孚 & $\begin{array}{l}\text { 离 } \\
\text { 告 }\end{array}$ & $\begin{array}{l}\text { 岕 } \\
\text { 岁 }\end{array}$ \\
\hline 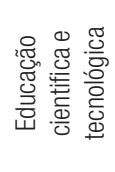 & 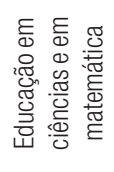 & 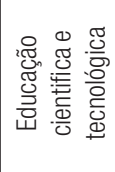 & 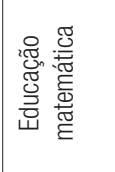 & 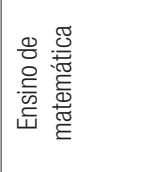 & 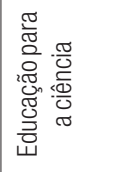 & 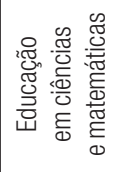 & 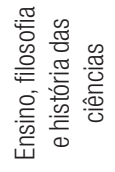 & 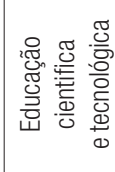 \\
\hline 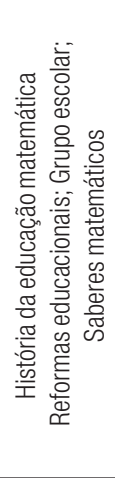 & 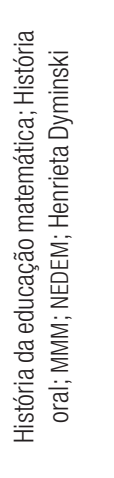 & 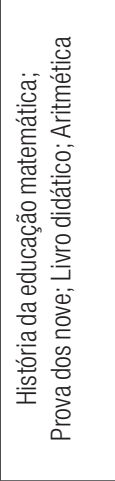 & 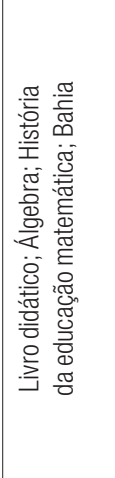 & 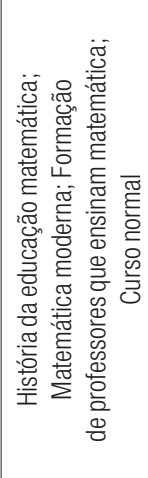 & 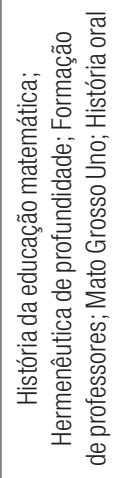 & 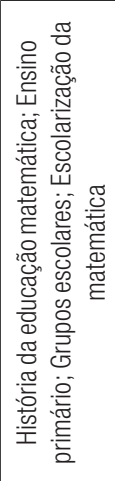 & 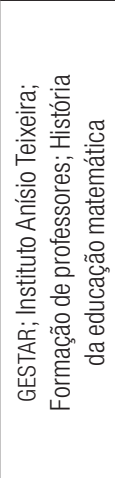 & 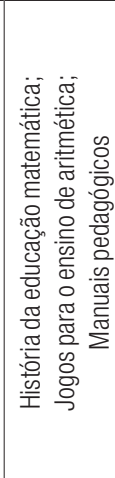 \\
\hline 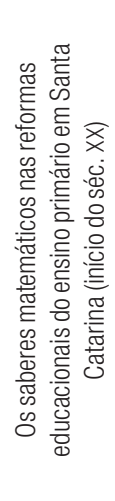 & 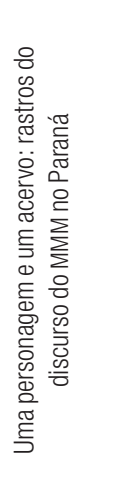 & 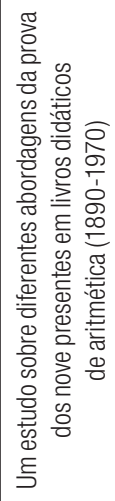 & 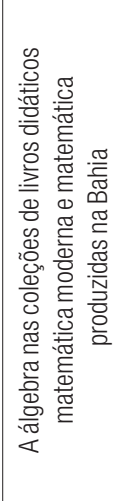 & 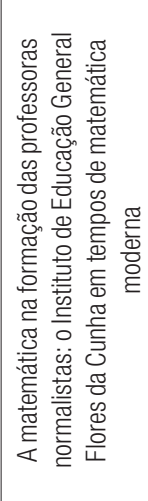 & 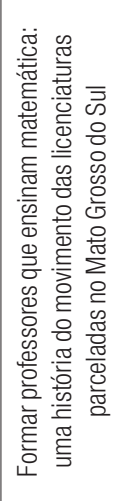 & 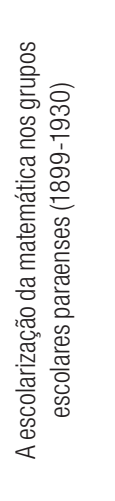 & 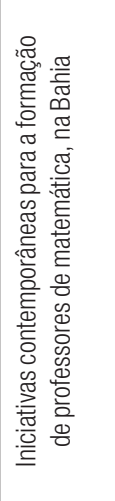 & 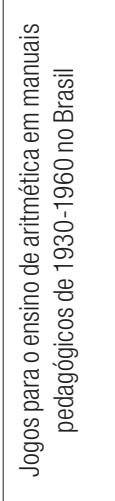 \\
\hline o & ○ & o & o & ○ & $\vdash$ & ○ & ○ & ○ \\
\hline 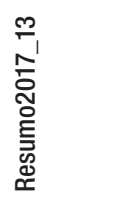 & 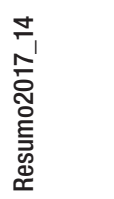 & 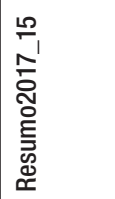 & 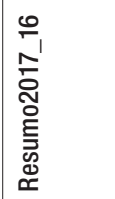 & 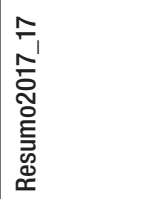 & 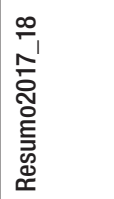 & 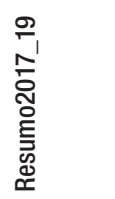 & 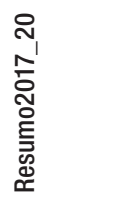 & 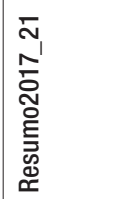 \\
\hline
\end{tabular}

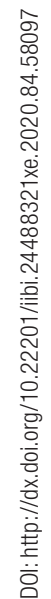




\begin{tabular}{|c|c|c|c|c|c|c|}
\hline के & $\sum$ & $\sum^{\infty}$ & ๙ & $\sum^{\infty}$ & $\sum$ & z \\
\hline 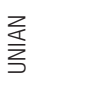 & $\sum_{3}^{\infty}$ & $\sum_{0}^{0}$ & 菊 & $\begin{array}{l}\text { 岀 } \\
\text { 号 }\end{array}$ & $\sum_{\text {岁 }}^{\infty}$ & 站 \\
\hline 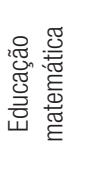 & 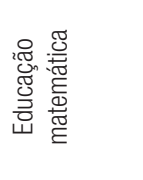 & 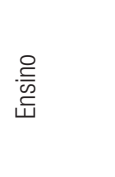 & 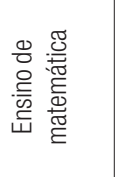 & 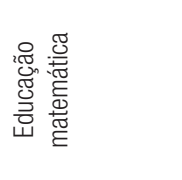 & 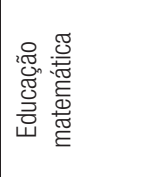 & 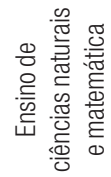 \\
\hline 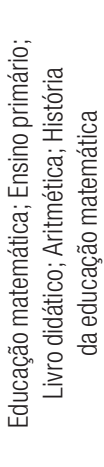 & 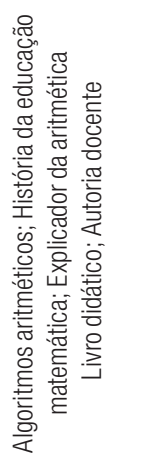 & 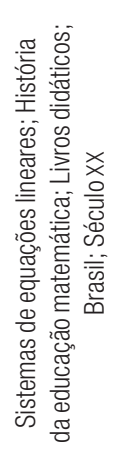 & 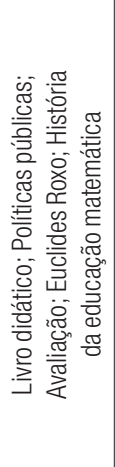 & 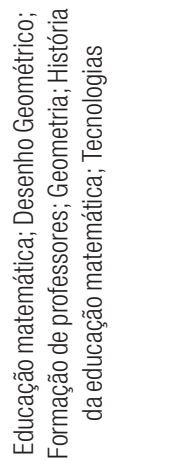 & 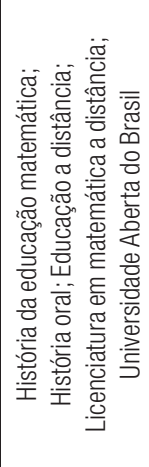 & 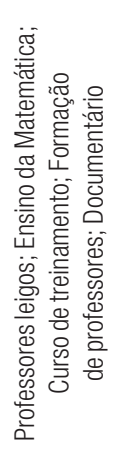 \\
\hline 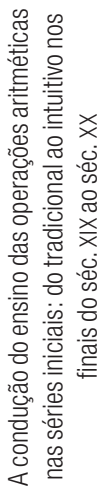 & 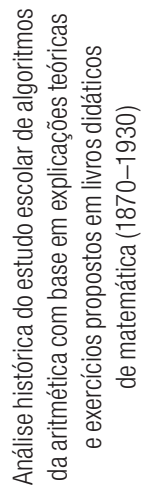 & 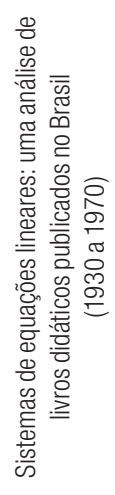 & 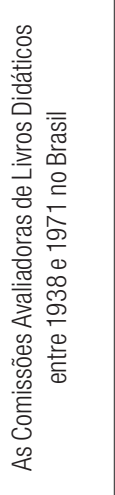 & 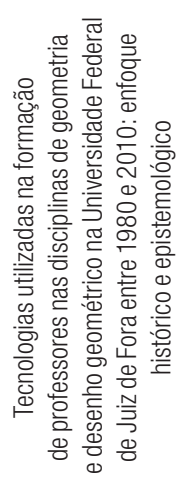 & 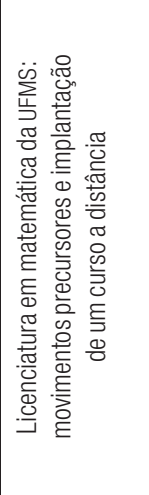 & 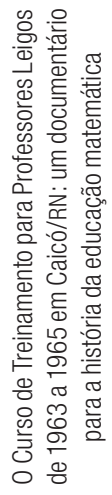 \\
\hline$\vdash$ & ○ & 口 & ○ & 口 & ○ & ○ \\
\hline 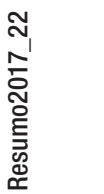 & 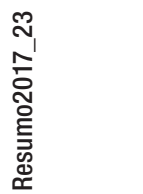 & 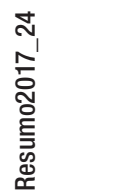 & 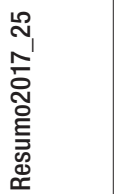 & 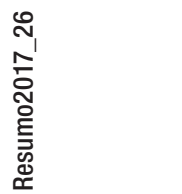 & 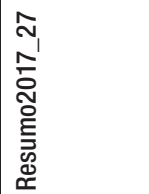 & 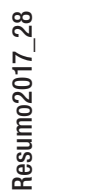 \\
\hline
\end{tabular}




\begin{tabular}{|c|c|c|c|c|}
\hline$\stackrel{\Upsilon 1}{\alpha}$ & $\sum^{\infty}$ & D & $\sum$ & के \\
\hline $\begin{array}{l}\frac{r}{0} \\
\text { Òㅁ } \\
\text { L }\end{array}$ & $\sum_{=}^{\infty}$ & $\begin{array}{l}\mathscr{y} \\
\text { 芒 } \\
\text { 品 }\end{array}$ & $\sum_{3}^{\infty}$ & $\begin{array}{l}\text { 崩 } \\
\text { 岸 }\end{array}$ \\
\hline 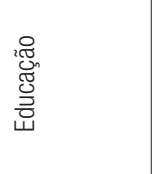 & 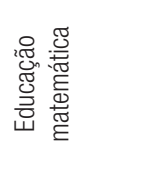 & 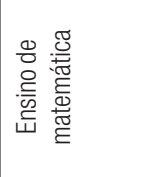 & 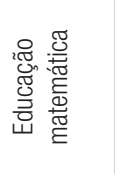 & 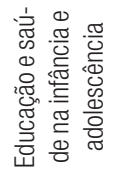 \\
\hline 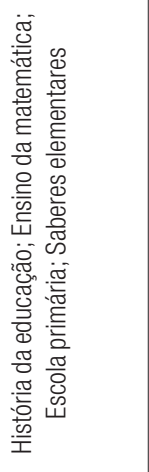 & 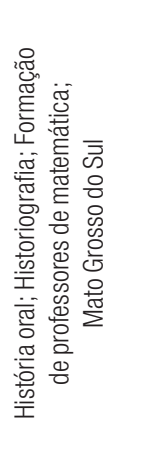 & 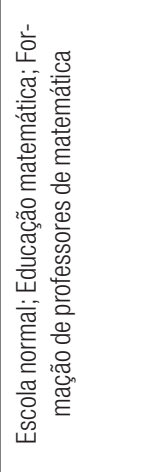 & 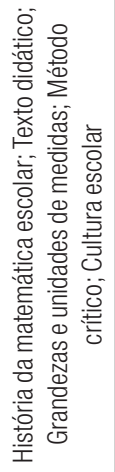 & 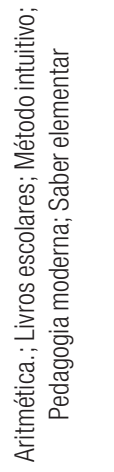 \\
\hline 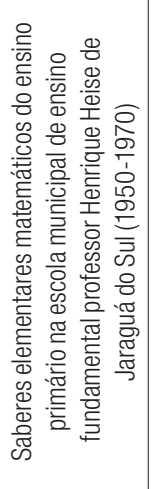 & 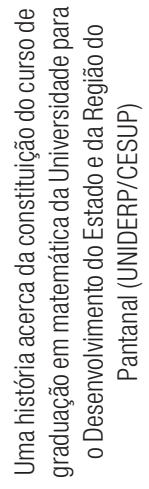 & 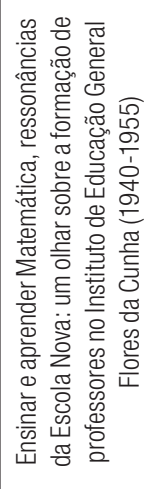 & 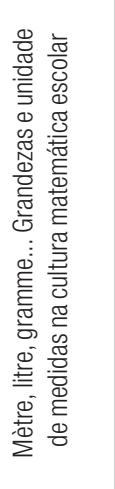 & 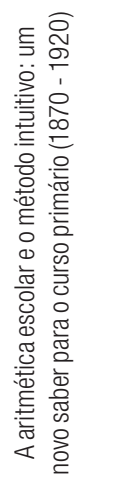 \\
\hline 口 & ○ & D & 口 & $\vdash$ \\
\hline 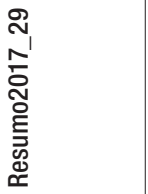 & 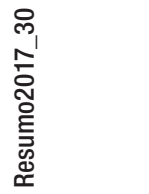 & 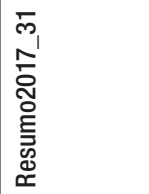 & 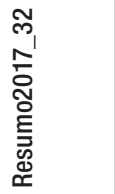 & 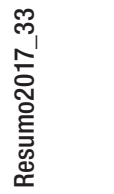 \\
\hline
\end{tabular}

